\title{
A Principled Approach to Research Conducted with Inuit, Métis, and First Nations People: Promoting Engagement Inspired by the CIHR Guidelines for Health Research Involving Aboriginal People (2007-2010)
}

Janet Jull

Queen's University, Kingston, Ontario, Canada, janet.jull@queensu.ca

Alexandra King

University of Saskatchewan, Saskatoon, Saskatchewan, Canada, alexandra.king@usask.ca

Malcolm King

University of Saskatchewan, Saskatoon, Saskatchewan, Canada, malcolm.king@usask.ca

Ian D. Graham

University of Ottawa, Ottawa, Ontario, Canada, igraham@ohri.ca

Melody E. Morton Ninomiya

Wilfrid Laurier University, Waterloo, Ontario, Canada, mmortonninomiya@wlu.ca

Kristen Jacklin

University of Minnesota Medical School Duluth, Duluth, Minnesota, USA, kjacklin@d.umn.edu

Penny Moody-Corbett

Northern Ontario School of Medicine, Thunder Bay, Ontario, Canada, pmoodycorbett@nosm.ca

Julia E. Moore

Centre for Implementation, Toronto, Ontario, Canada, julia.moore@thecenterforimplementation.com

Recommended Citation

Jull, J., King, A., King, M., Graham, I. D., Morton Ninomiya, M. E. Jacklin, K., Moody-Corbett, P., \& Moore, J. E. (2020). A principled approach to research conducted with Inuit, Métis, and First Nations people: Promoting engagement inspired by the CIHR Guidelines for Health Research Involving Aboriginal People (2007-2010). The International Indigenous Policy Journal, 11(2). doi: https://doi.org/10.18584/iipj.2020.11.2.10635 


\title{
A Principled Approach to Research Conducted with Inuit, Métis, and First Nations People: Promoting Engagement Inspired by the CIHR Guidelines for Health Research Involving Aboriginal People (2007- 2010)
}

\author{
Abstract \\ Research to address the health burdens experienced by Indigenous populations is essential. In the Canadian \\ context, the Truth and Reconciliation Commission of Canada determined that these health burdens are the result \\ of policies that have undermined opportunities to address community-level health needs. The Canadian Institutes \\ of Health Research Guidelines for Health Research Involving Aboriginal People (2007-2010), or "CIHR \\ Guidelines," were prepared in a national consultation process involving Inuit, Métis, and First Nations \\ communities, researchers, and institutions. This article asserts that the principles espoused in the CIHR Guidelines \\ hold ongoing potential to guide research with Indigenous people in ways that promote equitable research \\ partnerships. We encourage those in research environments to engage with the spirit and content of the CIHR \\ Guidelines.
}

\section{Keywords}

ethics, guidelines, research, CIHR Guidelines, TCPS2, Inuit, Métis, First Nations, Indigenous, engagement, equity

\section{Acknowledgments}

We are grateful for the important contributions to this paper by our valued colleague Dr. Jaime Flamenbaum. Drs. Alexandra King, Malcolm King, and Ian D. Graham are senior authors on the paper and provided important guidance and mentorship. We are grateful for and thank the Elders, Knowledge Holders, and community members who contributed to the development of the CIHR Guidelines for Health Research Involving Aboriginal People (2007-2010).

Funding Details: This work was supported by the Ontario SPOR Support Unit under grant \#60152 OSSU POR. IDG is a recipient of a CIHR Foundation Grant (FDN\# 143237).

\section{Creative Commons License (c) (1) @)}

This work is licensed under a Creative Commons Attribution-Noncommercial-No Derivative Works 4.0License. 


\section{A Principled Approach to Research Conducted with Inuit, Métis, and First Nations People: Promoting Engagement Inspired by the CIHR Guidelines for Health Research Involving Aboriginal People (2007-2010)}

Research is essential to address health inequities experienced by Indigenous ${ }^{1}$ populations (United Nations, n.d.). Inuit, Métis, and First Nations populations have the highest rates of health burden in relation to the general population living in Canada (Reading, 2009). These health burdens are the direct result of previous Canadian government policies that have undermined opportunities for Inuit, Métis, and First Nations populations to address community-level health needs and improve outcomes, as stated in the Truth and Reconciliation Commission of Canada (TRC, 2015a) Call to Action \#18 (see also Government of Canada, 1996; Ly \& Crowshoe, 2015; O'Neil, 1995). Inequities in health between Indigenous and general populations extend beyond Canada (Wilk, Cooke, Stranges, \& Maltby, 2017) and are evident in other colonial nations such as Australia, New Zealand, and the United States (Axelsson, Kukutai, \& Kippen, 2016; Czyzewski, 2011). These inequities are reflected in the determinants of health (King, Smith, \& Gracey, 2009; Reading \& Wein, 2009). Western-oriented ${ }^{2}$ views and values have been and continue to be privileged in colonial nations and are perpetuated by Westernoriented ways of knowing and doing (Akena, 2012; Smith, 2012). Western-oriented knowledge not only dominates research, it also drives the development of knowledge that is used in policy to structure health and social systems.

The history of research demonstrates an imbalance of power between Western-oriented researchers and their academic institutions, and the individuals and communities who attempt to engage in the research process. Such power imbalances in mainstream academic research systems typically characterize research as a process done "on" people, which has been described as distorting Indigenous knowledge, and viewed as "inquiry conducted by outsiders, harvesting information that is translated into distorted representations"(Brant Castellano \& Reading, 2010, pp. 2-3). Western-oriented research processes have contributed to the formulation of policies that are limiting and which undermine self-determination by Indigenous Peoples and their communities alike (Brant Castellano \& Reading, 2010). Deeply embedded in both health and social systems, the legacy of Western-oriented colonial practices and their ongoing perpetuation of inequity has had the effect of limiting opportunities for community members to

\footnotetext{
${ }^{1}$ We use the term Indigenous to refer to First Peoples internationally and as defined by United Nations (United Nations, n.d.):

Indigenous peoples are inheritors and practitioners of unique cultures and ways of relating to people and the environment. They have retained social, cultural, economic, and political characteristics that are distinct from those of the dominant societies in which they live. Despite their cultural differences, Indigenous peoples from around the world share common problems related to the protection of their rights as distinct peoples. (para. 1)

The term Aboriginal Peoples refers to the Indigenous inhabitants or the First Peoples of Canada including Inuit, Métis, and First Nations peoples, without regard to their separate origins and identities. For this reason, when referring to Indigenous people in Canada, we choose to convey the distinct origins and identities of Inuit, Métis, and First Nation groups.

${ }^{2}$ We use the term Western to refer to a worldview that is originally a product of European culture. Western is representative of an “... 'archive' of knowledge and systems, rules and values” (Smith, 2012, p. 44).
} 
be full and active participants in research and to contribute to research knowledge (Ball \& Janyst, 2008; Boffa, King, McMullin, \& Long, 2011; Jacklin \& Kinoshameg, 2008; Smith, 2012). To address these inequities and to take the kind of meaningful action called for by the TRC, Western-oriented research processes must evolve and create space for Indigenous knowledge and include roles for Knowledge Holders, Healers, Medicine People, and others in Indigenous communities. Further, research processes must avoid tokenism and begin to see these contributions as having equivalent value to Westernoriented ways of knowing. If we are unable to foster inclusivity in partnered knowledge creation, we will continue to fail to adequately explore and address Indigenous health and wellness ${ }^{3}$ knowledge and to understand the health needs of Indigenous people in society. The aim of this article is to assert that the principles of the CIHR Guidelines for Health Research Involving Aboriginal People (2007-2010) hold ongoing potential to provide a practical guide in research conduct with Indigenous people, in ways that promote equitable partnerships within Western-oriented academic settings (Canadian Institutes of Health Research [CIHR], 2007).

We are a team of Indigenous and non-Indigenous scholars who share a deep concern for the ways in which research often fails to consider the perspectives of Indigenous people, perpetuates injustice in our health and social systems, and contributes to health inequities. As researchers, we have been active in partnered research for many years. Some of our team were involved in the development of the CIHR Guidelines and have continued to further the development of ethical thought and practice with the objective of bringing forward Indigenous perspectives in research. Our goal in this article is to recognize the value of the principles espoused in the CIHR Guidelines. We present the practical guidance offered in the CIHR Guidelines as a useful option for Indigenous community members and Western-oriented researchers to engage with in spirit and content, should Indigenous communities not have guidelines to structure equitable research relationships.

\section{Background}

\section{The CIHR Guidelines for Health Research Involving Aboriginal People (2007-2010): A Strengths- Based Approach}

In a partnership with the Institute of Aboriginal Peoples' Health and the CIHR Ethics Office, the CIHR Guidelines were developed "to assist researchers and institutions in carrying out ethical and culturally competent research involving Aboriginal people” (CIHR, 2007, p. 2). The CIHR Guidelines were prepared by a collaborative working group composed of First Nations and Métis Elders as well as Indigenous researchers. The creation of the guidelines included a national consultation process involving Inuit, Métis, and First Nations communities, researchers, and institutions.

The guidelines themselves consist of 15 principles described through articles. Together, they provide clear guidance on how to conduct research that reflects, advances, and meets expectations for ethical, collaborative, and culturally supportive engagement with Inuit, Métis, and First Nations individuals and

\footnotetext{
${ }^{3}$ Well-being is a Western construct and more individualistic than the interconnected and wholistic wellness as conceptualized by many Indigenous people. There has been a gradual movement from wellbeing or well-being or well being to wellness (A. King \& M. King, personal communication, January 2019).
} 
communities. The purpose of our article is to encourage all those in research environments to engage with the principles of the CIHR Guidelines to: (a) operationalize required regulatory policy requirements and research directives; (b) ensure equitable inclusion of Indigenous and Westernoriented knowledge in research systems; and (c) in the case of Indigenous-specific enquiry, to privilege or to give primacy to Indigenous ways of knowing and doing (Gaudry \& Lorenz, 2018). Drawing on current and past research studies, we provide examples of the principled research practices described in the articles of the CIHR Guidelines.

We present the CIHR Guidelines as a useful option for Indigenous community members and Westernoriented researchers to use, should communities not have guidelines to structure equitable research relationships. The intent of the CIHR Guidelines is to promote research that is "in keeping with Aboriginal values and traditions" (CIHR, 2007, p. 2). The CIHR Guidelines provide foundational principles to guide the conduct of research, which may be of use to all researchers and researchers-intraining who engage in partnerships with Indigenous communities. The guidelines were prepared as an active response to the historical legacy of research, to address the need for greater community selfdetermination to achieve better health, and to redress the inappropriateness of many Western-oriented research approaches in Indigenous contexts. These factors historically contribute to ethical dilemmas and ineffective research outcomes (Warry, 1990). Furthermore, the CIHR Guidelines present an approach to research that upholds the strengths-based practices that are prevalent in Indigenous societies.

The CIHR Guidelines were originally developed to encourage and clarify the conditions for ethical research conduct, and to strategically inform the revision of the 1998 Tri-Council Policy Statement: Ethical Conduct for Research Involving Humans (TCPS; CIHR, Natural Science and Engineering Research Council [NSERC], \& Sciences and Humanities Research Council [SSHRC], 1998; see also Brant Castellano \& Reading, 2010). The TCPS is the joint research ethics policy statement of the federal research agencies, CIHR, NSERC, and SSHRC, referred to as "the Agencies." In 2010, CIHR's Governing Council approved the newly revised TCPS2 (CIHR et al., 2010). CIHR subsequently took the position that the TCPS 2 had precedence over the CIHR Guidelines, and the CIHR Guidelines were archived. In lieu, researchers were directed to the TCPS2 Chapter 9 that is described as drawing on the work from the CIHR Guidelines (CIHR et al., 2010). As will be discussed in more detail below, the focus of TCPS2 is on policy; that is, adherence to a set of ethical standards. It is not intended as a framework for how ethical and culturally appropriate research should be conducted. In other words, TCPS2 articulates what standards research must meet, but it does not inform researchers on how those standards should be attained. We argue that the CIHR Guidelines help to address this gap by providing a framework of principles for how ethical research can be conducted with Indigenous partners. The aim of our article is to highlight the guiding principles of the CIHR Guidelines.

Inuit, Métis, and First Nations populations have strengths and continuity within their societies (Cash, De Oliveira, Garrick, \& Hemi, 2014; Smylie, Olding, \& Ziegler, 2014); yet, these strengths are rarely acknowledged within mainstream academic research systems. When Indigenous knowledge is acknowledged, it is often from a Western-oriented perspective or interpretation. Additionally, Westernoriented knowledge is often considered more valid than other forms of knowledge, including knowledge arising from Indigenous experience (Akena, 2012). Healthcare rights and treaties need to be respected (Aboriginal Affairs and Northern Development Canada, 2007), and changes need to be made to health 
and social systems to foster greater inclusiveness of knowledge, including Indigenous knowledge. To improve the health and wellness of Indigenous communities, researchers must critically examine their own assumptions and biases in the process of knowledge development and consider their role in the interplay of power relationships in society (Jull \& Giles, 2012; Tobias, Richmond, \& Luginaah, 2013). When considering the conduct of research, there are important guiding documents: The Truth and Reconciliation Commission of Canada (TRC, 2015b) Final Report, United Nations Declaration on the Rights of Indigenous Peoples (UNDRIP; United Nations, 2007), and CIHR Guidelines (CIHR, 2007).

There are two key documents that assert the need to address societal imbalances of power that undermine opportunities for Indigenous Peoples' health and wellness, and which are relevant to the CIHR Guidelines. These are the TRC (2015a, 2015b) reports and UNDRIP (United Nations, 2007). The mandate of the TRC was to reveal the history of colonialism and its effects, which perpetuate to this day in Canada within Inuit, Métis, and First Nations contexts. The TRC (2015a) also made recommendations for reconciliation. Created by the Indian Residential Schools Settlement Agreement, the TRC involved three commissioners who spent six years listening to over 6,500 witnesses, which included Inuit, Métis, and First Nations people placed as children in residential schools under the direction of the Canadian government. The government's aim in creating the residential school system was to separate children from their families and communities with the purpose of indoctrinating children into the dominant Euro-Canadian culture (TRC, 2015b). In existence for over 100 years, residential schools have had a deleterious impact on many generations of Inuit, Métis, and First Nations people. A final report of the TRC (2015a) made recommendations for reconciliation that are framed as 94 Calls to Action. Of these, seven (Calls to Action \#18-24) relate specifically to health (TRC, 2015a). The aim of the TRC is to promote the establishment and maintenance of respectful relationships that can lead to societal change. Reconciliation is framed as a process of healing relationships that requires action. It is only through actions that we can address the ongoing legacy of colonial structures and processes to create an equitable and inclusive Canadian society (TRC, 2015b).

Another important document is UNDRIP (United Nations, 2007). UNDRIP promotes the individual and collective rights of Indigenous people and sets out the minimum standards for survival, dignity, and wellness. It promotes the rights of Indigenous people to have self-determination and to achieve the highest attainable health, in addition to other rights such as culture, identity, language, employment, and education (Inter-Parliamentary Union, 2014). As a guiding document, the UNDRIP encourages nations to work with Indigenous people in appropriate and culturally resonant ways to design legislation, policies, and programs to stop the perpetuation of inequity and the further marginalization of Indigenous people (Assembly of First Nations, 2017). Both the TRC and UNDRIP stress that it is important to promote actions that do not risk perpetuating or reproducing existing colonial structures in research. As well, these documents explain why it is important to take action in the area of research in ways that Indigenous people identify as respectful and inclusive. The CIHR Guidelines have been identified as upholding the spirit and intent of the UNDRIP (Taniguchi, Taualii, \& Maddock, 2012) and supporting processes that structure action to address TRC recommendations. The CIHR Guidelines were developed by and with Indigenous-led scholars, organizations, and community members who envisioned opportunities for societal change through the ethical conduct of research. 


\section{Analysis}

\section{Ethical Conduct of Research with Indigenous People: A Need for Practical Guidance}

The imposition of Western-oriented approaches to research "on" Indigenous groups is coming under increasing scrutiny by those in mainstream academic research systems, including researchers and those who are impacted by research, such as members of the public, health systems policy and decision makers, and care providers (Akena, 2012; Brant Castellano \& Reading, 2010; Jacklin \& Kinoshameg, 2008). This scrutiny has led to greater efforts to accommodate diverse conceptualizations of knowledge in health and social systems, including Indigenous knowledge systems fostered by participatory processes and resulting in research collaboration. Collaborative research is defined as a genuine, meaningful partnership between researchers and the community and its members affected by the research; collaborative research promotes a partnership within a framework of mutual trust and cooperation throughout the entire the research process (CIHR, 2007). Evidence indicates that the use of participatory processes in research is linked to increased collaboration among community partners and researchers (Israel et al., 2006). Participatory processes in research prioritize partnerships with people for whom the research is ultimately meant to be of benefit. The use of such processes in research have been identified as a means to address power inequities while also generating research findings that are more likely to produce useful outcomes (Jull, Morton-Ninomiya, Compton, \& Picard, 2018; Masuda, Zupancic, Crighton, Muhajarine, \& Phipps, 2014; Tobias et al., 2013). Despite the imperative for collaborative research, practical guidance on how to conduct research that is inclusive of Indigenous communities and their members, or how to incorporate the perspectives of Inuit, Métis, and First Nations groups remains limited (Morton Ninomiya \& Pollock, 2017). There is an urgent need for increased knowledge of ways to operationalize principled research practices that engage Indigenous groups, reconceptualising and transforming our approaches to research with Indigenous people and shifting the balance (Gaudry \& Lorenz, 2018).

Public policy is a powerful lever for change, and it can be used to address the imbalances that exist in society, including our research and health systems. A principled approach to research that is consistent with contemporary ethics policy, may lead to genuine, meaningful partnerships between researchers and those whom the research is meant to benefit. It is from within these genuine relationships that opportunities emerge to redistribute power and allow those who hold knowledge to lead change, wherever they might be positioned in the research relationship.

In Canada, research designs that involve humans must demonstrate adherence to policy for ethical standards articulated in the TCPS2 (CIHR et al., 2018). The TCPS (CIHR et al., 1998) promotes the ethical conduct of research involving humans: "It outlines standards and procedures for research involving humans and applies to those conducting, participating in, or reviewing human research in institutions funded by the Agencies" (para. 1). The TCPS document is a policy statement on the ethical conduct of research involving humans. In 2010, the second version of TCPS, referred to as TCPS2, was released (CIHR et al., 2010). TCPS2 introduced a new chapter, Chapter 9 "Research Involving the First Nations, Inuit and Métis Peoples of Canada," about Indigenous research. The aim of TCPS2 Chapter 9 is to provide specific governance for research that involves First Nations, Inuit, and Métis people and to be used with any codes of research practice established by Indigenous communities themselves. The TCPS2 (2010) was further revised in 2014 without changes to Chapter 9, and the TCPS2 (2018) is now 
the official research ethics policy of the Agencies (CIHR et al., 2010, 2014, 2018). Policy-based research guidance, such as the TCPS2, primarily outlines criteria for ethical conduct. It offers little to guide researchers on approaches that promote and support ethical behaviour in the conduct of their research.

The approach of the TCPS2 is in contrast to the CIHR Guidelines: The CIHR Guidelines, as a guiding document developed by and for Indigenous communities, demonstrates steps in how to conduct research that is beneficial for Indigenous communities (Brant Castellano \& Reading, 2010). The TCPS2 articulates what researchers must do, but it is limited in that it does not help researchers understand how to do research in a way that is beneficial for Indigenous communities. To ensure that community members and research collaborators are not undervalued in Western-oriented and biased health and social systems, it is critical that researchers develop understandings of how to use ethically sound approaches in the conduct of their research.

One other limitation inherent in the sole use of a policy that articulates ethical standards is that such a policy may not go far enough to address the balance of power in research partnerships (Brunger \& Wall, 2016; Moore, Castleden, Tirone, \& Martin, 2017). The failure to address the balance of power in the conduct of research is of tremendous importance given the history of inequity for Indigenous people in research (Allen \& Flamenbaum, 2013). There is a need to facilitate respectful research processes of knowledge development that are inclusive of and centred on Indigenous ways of knowing and doing. This may require expanding upon the limits of Western-oriented approaches to research. Awareness has grown within the Indigenous and Western-oriented academic research community about historical and ongoing injustices associated with research involving Indigenous people. Each community has a unique local culture and research needs, from which meaningful research relationships may be built (Baydala et al., 2014; Pahwa et al., 2015). There are examples of research guidance developed to structure the ethical conduct of research with Indigenous people internationally and more locally in Canada with Inuit, Métis, and First Nations populations. Many Indigenous communities and organizations in Canada are at various stages of creating their own independent research ethics guidelines and protocols that explain an ethical approach to the conduct of research (see examples in Table 1).

The CIHR Guidelines were designed for use by locally established Indigenous ethics review committees, Western-oriented researchers and research ethics boards, as well as individuals and communities, to know what to expect of a research partnership. They are described as "intended to promote ethics review that enables and facilitates rather than supresses or obstructs research” (CIHR, 2007, p. 12). The CIHR Guidelines were intended to provide a template for an ethical approach to research when communities do not have their own guidelines in place, and for those who use the CIHR Guidelines to reach consensus on research protections that are appropriate to the context (CIHR, 2007). 
Table 1. Some Examples of International, National, and Local (Within Canada) Research Ethics Guidance

International Indigenous People and Participatory Health Research (World Health Organization, n.d.)

National Tri-Council Policy Statement: Ethical Conduct for Research Involving Humans

(Chapter 9; CIHR et al., 2018)

Ethical Conduct in Research with Aboriginal and Torres Strait Islander Peoples and Communities: Guidelines for Researchers and Stakeholders (National Health and Medical Research Council, 2018)

Guidelines for Researchers on Health Research Involving Maori (Health Research Council of New Zealand, 2010)

Indigenous Research Protection Act (Indigenous Peoples Council on Biocolonialism, 2000)

The First Nations Principles of OCAP ${ }^{\otimes *}$ (First Nations Information Governance Centre, 2018)

National Inuit Strategy on Research (Inuit Tapiriit Kanatami, 2018)

Negotiating Research Relationships with Inuit Communities: A Guide for Researchers (Inuit Tapiriit Kanatami \& Nunavut Research Institute, 2007)

Principles of Ethical Métis Research (National Aboriginal Health Organization, 2010)

Proposal for Ethical Guidelines for Sámi Health Research and Research on Sámi Human Biological Material (Samediggi, 2018)

Local Guidelines for Ethical Aboriginal Research (Noojmowin Teg Health Centre, 2003)

(Examples

from Canada) Protocols and Principles for Conducting Research with Yukon First Nations (Yukon Research Centre, 2013)

Guidelines for Community Engagement with NunatuKavut (NunatuKavut Community Council Research Advisory Committee, 2013)

Kahnawake Schools Diabetes Prevention Project (KSDPP): Code of Research Ethics (Revised 2007; KSDPP, 2007)

Sturgeon Lake First Nation Research Protocol (Sturgeon Lake Health Center Centre, personal communication, March 2019)

Note. ${ }^{*} \mathrm{OCAP}^{\circledast}$ is a registered trademark of the First Nations Information Governance Centre (FNIGC). 


\section{The Benefits of a Principled Approach to Research}

The CIHR Guidelines were developed to engage Indigenous communities and community members and Western-oriented researchers in the collaborative design and conduct of research to best meet the needs of those engaged in or affected by the research endeavour. There are examples of research studies that have used a principled approach with success. For instance, there are major gaps in health data of Indigenous groups, and the collection of health data of Indigenous people has a history of colonization and discrimination (National Collaborating Centre for Aboriginal Health, 2012). Recently, the environment of health data has been changing to reflect principles of good governance of Indigenous data. There is an emerging data sovereignty movement that maps onto the First Nations' principles regarding the collection, use, and disclosure of data or information regarding First Nations. Ownership, Control, Access, and Possession $\left(\mathrm{OCAP}^{\circledast}\right)$ principles, for example, articulate key principles for First Nations' data governance (First Nations Information Governance Centre, 2018; Walker, Lovett, Kukutai, Jones, \& Henry, 2017). Guided by the principles of good governance of Indigenous data, a study linked the Indian Register to routinely collected provincial health administrative data for First Nations individuals living in the province of Ontario, Canada. The data made it possible for Indigenous organizations and communities to identify and take ownership of the data and ask questions of researchers that are important to them, such as cancer survival rates and child wellness indicators (Walker et al., 2017). Principled approaches to research can lead to research practices that are truly collaborative, strengths based, of mutual benefit, and culturally appropriate. As the CIHR Guidelines promote inclusion of Indigenous knowledge in research systems, they support the use of $\mathrm{OCAP}^{\circledR}$ and other Indigenous-developed approaches critical for self-determination and self-governance. The CIHR Guidelines hold ongoing potential to guide research with Indigenous people in ways that Indigenous groups themselves have identified as able to promote equitable partnerships.

\section{The Use of the CIHR Guidelines as a Complement to Policy and to Guide Research Action}

The ways to develop and sustain partnerships with Inuit, Métis, and First Nations groups with Westernoriented academic research partners in such ways that all members of the partnership can define as ethical and equitable are not yet clear. It is important to find common ground on ways to talk about research conduct and to enact policy that promotes equitable partnerships. We must better understand how to operationalize research principles that align with and uphold Indigenous values and traditions in Western-oriented academic settings. These principles must be strengths based, of mutual benefit, and able to be identified as culturally appropriate and safe by those participating or affected by research partnerships. Inuit, Métis, and First Nations people must be able to identify research as done byand with their communities and be fully confident that research aims are addressing priorities that are of importance to each community.

The CIHR Guidelines are "not regulations nor are they meant to be of general application. Rather, they are guidelines that should be followed by anyone who carries out research involving Aboriginal people in Canada" (CIHR, 2007, p. 2). An established CIHR working group called the Aboriginal Ethics Working Group (AEWG) prepared the CIHR Guidelines. The AEWG included Elders as well as Indigenous researchers. Together with leaders from a range of academic disciplines, they provided advice and support during a broad national two-year series of consultations to develop research ethics guidelines for Inuit, Métis, and First Nations people in a process that has been described elsewhere (Brant Castellano 
\& Reading, 2010). The national Aboriginal Capacity and Developmental Research Environments (ACADRE) network also informed the work. The national consultation process with Inuit, Métis, and First Nations Elders and communities, researchers, and institutions resulted in the CIHR guidelines that promote "ethical and culturally competent" research involving Inuit, Métis, and First Nations people (CIHR, 2007, p. 2). Some of the authors of this article were active in the process of developing the CIHR Guidelines.

The CIHR Guidelines were designed to promote particular research actions, as well as:

- Be applicable to researchers funded by CIHR who were carrying out research involving Inuit, Métis or First Nations people in Canada;

- Be voluntarily implemented by the researcher, in return for CIHR funding; and

- Be a complement to the mandatory use of Tri-Council and funding agency policies as well as any other applicable legislation such as the Canadian Charter of Rights and Freedoms.

\section{CIHR Guidelines: Potential to Guide Research Conduct}

Following the release of TCPS 2 in 2010, CIHR archived the CIHR Guidelines and made the TCPS2 the sole policy on Indigenous research among the federal funding agencies. As a team of Indigenous and non-Indigenous scholars, we believe that the articles and principled approach promoted in the CIHR Guidelines continue to have value as a complement to policy governing ethical standards. Moreover, they provide pragmatic and practical guidance for researchers and Indigenous communities who are interested in how to conduct research that is strengths based, of mutual benefit, and culturally appropriate. Researchers who are unfamiliar with the conduct of collaborative research with Indigenous communities may benefit from the application of the CIHR Guidelines. The CIHR Guidelines may help to prepare researchers to create opportunities to respect, honour, and utilise Indigenous knowledge when conducting research with Indigenous people. For instance, as there are new research methods that seek to include Indigenous and Western-oriented approaches together, researchers must be particularly attentive to ensure that they care for and protect sacred knowledge, which may include ceremonial knowledge. In some cases, Indigenous ways of knowing and doing may not be openly shared. For instance, current Knowledge Holders may be uniquely responsible for the intergenerational transmission of knowledge or practices from ancestors to future generations within a given community. The CIHR Guidelines promote approaches to research with Indigenous people that stress the need to identify, care for, and protect sacred knowledge. Further, the CIHR Guidelines more fully respect Indigenous ways of research- "research is not only ceremony, but also ceremony can be research" (A. King, personal communication, October 2018).

The conduct of research that leads to knowledge development to support the health and wellness of Indigenous people must adopt an approach that is led by Indigenous people-and Western-oriented academics must respect Indigenous partners' guidance. The CIHR Guidelines, with its principled approach, sets the conditions for equitable relationships, so that Indigenous ways of knowing are honoured and respected in forums that might otherwise be dominated by Western-oriented academic ways of knowing.

We assert that the principles of the CIHR Guidelines hold the potential to guide research with Indigenous people in ways that promote equitable partnerships within Western-oriented academic 
settings. We encourage all those in research environments to engage with the principles of the CIHR Guidelines as an approach to (a) operationalize required regulatory requirements and research directives (that is, policy), and (b) ensure equitable inclusion of Indigenous and Western-oriented knowledge in research systems. Drawing on current and past research studies, we provide examples of the principled research practices described in the articles of the CIHR Guidelines (CIHR, 2007; Table 2).

Table 2. CIHR Guidelines: Demonstration of Principled Research Practices Described in Articles with Examples

\begin{tabular}{ccc}
\hline & Key Features: Possible Ways to Demonstrate & Principles \\
CIHR Guidelines & Principles \\
\hline
\end{tabular}

\section{Principle \# 1: Reconciliation of Ethical Spaces}

"Protecting Aboriginal ethical space involves a series of stages of dialogue beginning with the conversations prior to the design of the research, through to the dissemination of results and perhaps even afterward. Fundamental to this process is an ongoing respect for both parties' ethical spaces and a continual questioning of 'is this ethical?" This requires a dialogue about intentions, values and assumptions throughout the research process" (CIHR, 2007, p. 17).

\section{Principle \#2: Sacred Space and Traditional Knowledge}

\section{Article 1:}

"A researcher should understand and respect Indigenous world views, including responsibilities to the people and culture that flow from being granted access to traditional or sacred knowledge. These should be incorporated into research agreements, to the extent possible" (CIHR, 2007, p. 17).
- Spend time in the community: Volunteer, attend community events, meet with Elders, demonstrate intent to form longerterm relationship (extends before and after the research).

- Establish common ground: Make efforts to understand what matters to collaborators, including what and how knowledge can be collected and shared.

- Show public accountability: Articulate why the research is urgently needed, with clear implications for the future. It is important to do this research for now and the future.
In a paper by Baydala et al. (2014), the ways in which co-learning, cocreation, and community-based participatory research are used in a partnered research project is presented. Authentic partnering in research (if not already formed) often requires significant amounts of time building relationships, trust, and developing a research plan in which the community is invested. 
Table 2. CIHR Guidelines: Demonstration of Principled Research Practices Described in Articles with Examples (continued)

Key Features: Possible Ways to Demonstrate

CIHR Guidelines $\quad$ Principles $\quad$ Examples

\section{Principle \#3: Community Control and Approval Process}

Article 2:

"A community's jurisdiction over the conduct of research should be understood and respected. This article should be read in the context of the discussion in Section 1.5, which addresses the application of this document" (CIHR, 2007, p. 18).
- Identify community processes: Who decides and guides research data responsibilities and processes?

- Develop agreement(s): Memorandum of understanding (MOU), terms of reference, traditional agreements, or other ways to explicitly demonstrate consensual agreement between parties.

- Be open to an evolving process: $\mathrm{A}$ community may not have a specific research protocol, but members may want to explore, consult, and guide research.

\section{Principle \#4: Participatory Research}

\section{Article 3:}

"Communities should be given the option of a participatory-research approach" (CIHR, 2007, p. 19).
- Ensure opportunities for communities to define what is participatory: Communities decide how much community participation is desired and reasonable, especially human and in-kind resources. Researchers bring some skills and knowledge, but they rarely have expertise on context and values.

- Show clear evidence of collaboration and partnership in the research process: There must be a shared responsibility in identifying the importance of an issue as well as planning, conducting, and disseminating results.

- Show respect for community and other stakeholder values: This can include revisiting and checking in on the research process, and adherence to and respecting local traditional values in the research work.

- Develop capacity for community and others to be partners if desired by community: Ensure others benefit from research, and plan to share gains from work fairly.
In a study by Pahwa et al. (2015) that explored respiratory health of First Nations people living on reserves, housing inadequacies were identified to be a key underlying determinant of respiratory ill health. As a result, the research agenda turned to addressing housing design issues.

Jull, Giles, Minwaashin Lodge, the Aboriginal Women's Support Centre, Boyer, and Stacey (2015) described the process by which a predetermined collaborative research approach was established. This demonstrated the terms of the research study in multiple ways, including through an ethical framework, research agreements, inclusion of Minwaashin Lodge on ethics, and a co-published protocol. In addition, the researcher was encouraged to be an active member of the community and hired a community-recommended member as research assistant. 
Table 2. CIHR Guidelines: Demonstration of Principled Research Practices Described in Articles with Examples (continued)

Key Features: Possible Ways to Demonstrate

CIHR Guidelines $\quad$ Principles $\quad$ Examples

\section{Principle \#5: Community and Individual Consent}

Article 4:

"A researcher who proposes to carry out research that touches on traditional or sacred knowledge of an Indigenous community, or on community members as Indigenous people, should consult the community leaders to obtain their consent before approaching community members individually. Once community consent has been obtained, the researcher will still need the free, prior, and informed consent of the individual participants" (CIHR, 2007, p. 20).

\section{Article 5:}

"Concerns of individual participants and their community regarding anonymity, privacy and confidentiality should be respected and should be addressed in a research agreement" (CIHR, 2007, p. 21).
- Identify local community governance structures and processes for gaining approval for engaging community members.

- Present research idea(s) to community leaders.

- Create opportunities for community leaders and members to learn about the researcher(s) and the research as well as respond.

- Articulate how research and researchers aim to have the process and outcome(s) benefit the community or individuals involved in a study - a higher bar than the common favourable risk-benefit expectation in research involving people.

Principle \#6: Confidentiality and Privacy

- Identify concerns around individual and community protections of information.

- Ensure agreements are stated and addressed, ideally in research agreements.
Brunger and Wall (2016) critically examined the ways in which researchers who follow research ethics guidelines can reinforce colonialist power relations through taken-forgranted assumptions. In this paper, the findings from a research study that engaged Southern Inuit and NunatuKavut members are used to describe and operationalize the concept of research collaboration.
In a study to evaluate potential health determinants, a project was conceptualized and developed through two years of dialogue with participating First Nations communities. An agreement was created that addressed issues such as researcher and community coownership of data and how confidentiality and privacy would be respected (Pahwa et al., 2015). 
Table 2. CIHR Guidelines: Demonstration of Principled Research Practices Described in Articles with Examples (continued)

Key Features: Possible Ways to Demonstrate

CIHR Guidelines $\quad$ Principles $\quad$ Examples

\section{Principle \#7: Inclusion and Protection of Cultural Knowledge in Research}

Article 6:

"The research agreement should, with the guidance of community knowledge holders, address the use of the community's cultural knowledge and sacred knowledge" (CIHR, 2007, p. 22).
- Discuss and agree on co-authorship and acknowledgments in academic forms of dissemination early in the study:

Dissemination may include papers, reports, and other forms.

- Come to agreement with community stakeholders on how and who to acknowledge in future work by researcher.

\section{Article 7:}

"Aboriginal people and their communities retain their inherent rights to any cultural knowledge, sacred knowledge, and cultural practices and traditions which are shared with the researcher. The researcher should also support mechanisms for the protection of such knowledge, practices, and traditions" (CIHR, 2007, p. 22).
- Be transparent in the use and development of knowledge (include community partners on or provide them with access to ethics applications, academic and community papers, reports, and presentations).

- Agree on co-authorship and other research and community-based opportunities (for example, engage a community-based research assistant, conduct community presentations, et cetera).

- Demonstrate evidence of guidance about knowledge use - Knowledge holder or Elder consultations and/or participation to ensure ongoing permissions; community guidance on use of knowledge.
In a study by Castleden, Morgan, and Neimanis (2010), 15 researchers at Canadian universities who conducted community-based participatory research with Indigenous communities were interviewed. The study reported on the diverse practices of acknowledgments and coauthorship, including the benefits and risks of co-authorship with collectives or community partners.

In a paper by Kelley Belcourt-Dittloff, Belcourt, and Belcourt (2013), the Tribal board protocols for reviews of how Indigenous knowledge is used, shared, and incorporated into research practices in the United States are examined and discussed. Written documentation between researchers and a Tribal board include (a) clear language descriptions of the study, (b) how cultural knowledge, language, and practices are to be incorporated into the study, and (c) the resource allocation to support the involvement of Tribal community Elders and community members. 
Table 2. CIHR Guidelines: Demonstration of Principled Research Practices Described in Articles with Examples (continued)

Key Features: Possible Ways to Demonstrate

CIHR Guidelines $\quad$ Principles $\quad$ Examples

\section{Principle \#8: Intellectual Property Rights and Indigenous Knowledge}

\section{Article 8:}

"Community and individual concerns over, and claims to, intellectual property should be explicitly acknowledged and addressed in the negotiation with the community prior to starting the research project. Expectations regarding intellectual property rights of all parties involved in the research should be stated in the research agreement" (CIHR, 2007, pp. 22-23).

\section{Article 9:}

"Research should be of benefit to the community as well as to the researcher" (CIHR, 2007, p. 23).
- Plan for outcomes (products, sustainability) clearly articulated at start of research.

- Ensure there is evidence that community wishes were sought and honoured.

- Confirm and re-confirm permissions and keep community collaborators informed.

- Explore using a participatory research approach — fair benefits in sharing of research.

\section{Principle \#9: Benefit Sharing}

- Specify who the beneficiaries of research will be.

- Assess importance of the health issues investigated and prospective values of research for beneficiaries.

- Enhance value of research for each of the beneficiaries through discussion of knowledge, products, long-term research collaboration, health system improvements.
Baydala et al. (2014) culturally adapted a life skills training program aimed at school-aged children and youth in a First Nation community, which was then evaluated using community-based participatory research methods. In the paper that describes the positive aspects of the program, the authors highlight the ways in which Elders were central to the program adaptations, and how the process of evaluation involved community researchers in all phases, from data collection to dissemination.

In a study by Tobias et al. (2013), a community-based approach revealed environmental and health issues among Anishinabe communities in a region of Ontario, Canada. The authors described how commitment to reciprocity and relational accountability meant making all attempts to meet community needs throughout all stages of the research process. 
Table 2. CIHR Guidelines: Demonstration of Principled Research Practices Described in Articles with Examples (continued)

\begin{tabular}{ccc}
\hline & Key Features: Possible Ways to \\
Demonstrate Principles & Examples \\
\hline
\end{tabular}

\section{Principle \#10: Empowerment and Research Capacity Development}

Article 10:

"A researcher should support education and training of Indigenous people in the community, including training in research methods and ethics" (CIHR, 2007, p. 23).
- Explain how research benefits community and researcher.

- Researcher(s) spend time in the community and with community members, evidence that they build their understandings of community and readiness.

- Researcher(s) build capacity in the community, for example, by hiring community research assistant and training community members.

- Publish and disseminate research findings in accessible ways to community, such as publishing in open access journals and using different formats (such as in-person communications) that suit different communication styles.
A study by Allen et al. (2006) described how Alaskan Native coresearchers without specialist research training were involved in all stages of the study. As a result, the coresearchers insisted on effective ways for research findings to be shared within the community, co-researchers with new skills were valuable to the community, and academic researchers benefitted from having credible and valid findings that were valued by the Alaskan Native communities and other researchers alike.

\section{Principle \# 11: Cultural Protocol, Language and Communication}

Article 11:

11.1 "A researcher has an obligation to learn about, and apply, Indigenous cultural protocols relevant to the Indigenous community involved in the research."

11.2 "A researcher should, to the extent reasonably possible, translate all publications, reports and other relevant documents into the language of the community."

\section{3 "A researcher should} ensure that there is ongoing, accessible and understandable communication with the community" (CIHR, 2007, p. 24).
- Reflect community communication preferences and include evidence of application of local cultural protocols and language.

- Facilitate accessible and ongoing communications with community partners.
In a study called the Indigenous Red Ribbon Storytelling Study by Nowgesic, Meili, Stack, and Myers (2015), small tobacco bundles were offered to each research participant in addition to hosting a traditional Indigenous feast as part of a sharing circle of participants. 
Table 2. CIHR Guidelines: Demonstration of Principled Research Practices Described in Articles with Examples (continued)

\begin{tabular}{ccc}
\hline & Key Features: Possible Ways to \\
Demonstrate Principles & Examples \\
\hline
\end{tabular}

\section{Principle \# 12: Initial and Secondary Use, Proprietary Interest, Storage, and Transfer of Data and Biological Samples}

Article 12:

12.1 "A researcher should recognize and respect the rights and proprietary interests of individuals and the community in data and biological samples generated or taken in the course of the research" (CIHR, 2007, p. 24).

12.2 "Transfer of data and biological samples from one of the original parties to a research agreement to a third party requires consent of the other original party or parties" (CIHR, 2007, p. 24).

12.3 "Secondary use of data or biological samples requires specific consent from the individual donor and, where appropriate, the community. However, if the research data or biological samples cannot be traced back to the individual donor, then consent for secondary use need not be obtained from the individual. Similarly, if research data or biological samples cannot be traced back to the community, then its consent for secondary use is not required" (CIHR, 2007, p. 24).
- Show evidence of agreed-upon approach such as a set of criteria or agreement (for example, OCAP $^{\circledast}$ ).

- Have evidence that agreements are adhered to and, if changed, there is evidence that agreements were adjusted (including changes related to publications, use of reporting guidelines, et cetera).

- Demonstrate respect for recruited participants and study communities by developing and implementing procedures to protect confidentiality; provide participants with information that arises in study; ensure enrolled participants cared for, mitigating harms from the study; inform participants and community of results.

- Concepts of data sovereignty are explicit and adhered to.

- Provide description of anonymization process.

- Provide documentation such as reports to institutional and community ethics boards.

- Document evidence that the consultation took place.
A study with Māori by Hudson et al. (2016) explored how to consider and include Māori rights and interests in research that involves biobanking and genomics. In their paper, the authors highlight six key areas of consideration regarding biobanking and genetic research-with particular emphasis on Māori participation in research governance, transparency, and accountability to communitiesand they share how Māori rights and interests are to be protected. 
Table 2. CIHR Guidelines: Demonstration of Principled Research Practices Described in Articles with Examples (continued)

\begin{tabular}{|c|c|c|}
\hline CIHR Guidelines & $\begin{array}{c}\text { Key Features: Possible Ways to } \\
\text { Demonstrate Principles }\end{array}$ & Examples \\
\hline $\begin{array}{l}12.4 \text { "Where the data or } \\
\text { biological samples are known } \\
\text { to have originated with } \\
\text { Indigenous people, the } \\
\text { researcher should consult with } \\
\text { the appropriate Indigenous } \\
\text { organizations before initiating } \\
\text { secondary use" (CIHR, 2007, } \\
\text { p. } 25 \text { ). }\end{array}$ & $\begin{array}{l}\text { Document evidence of process and } \\
\text { agreements, such as meeting notes and } \\
\text { agreements. } \\
\text { - Make reference to processes (such as } \\
\text { OCAP }^{\circledR} \text { ) or other community-endorsed } \\
\text { policies. }\end{array}$ & \\
\hline $\begin{array}{l}12.5 \text { "Secondary use requires } \\
\text { REB review. The guidelines set } \\
\text { out basic principles for the } \\
\text { collection, disclosure, use, and } \\
\text { transfer of data and biological } \\
\text { samples" (CIHR, 2007, p. } 25) \text {. }\end{array}$ & & \\
\hline \multicolumn{3}{|c|}{ Principle \# 13: Biological Samples on Loan } \\
\hline $\begin{array}{l}\text { Article 13: } \\
\text { "Biological samples should be } \\
\text { considered "on loan" to the } \\
\text { researcher unless otherwise } \\
\text { specified in the research } \\
\text { agreement" (CIHR, 2007, p. } \\
25 \text { ). }\end{array}$ & $\begin{array}{l}\text { Evidence of data sharing agreements and } \\
\text { reference to the use of process that follow } \\
\text { community endorsed policies and } \\
\text { principles. }\end{array}$ & $\begin{array}{l}\text { A paper by Kowal, } \\
\text { Pearson, Peacock, Jamieson, and } \\
\text { Blackwell (2012) presents a review of } \\
\text { the literature and ethical issues } \\
\text { relevant to genetic research in } \\
\text { Indigenous populations. The ways in } \\
\text { which these issues are negotiated } \\
\text { within a particular genomic research } \\
\text { project that involves the rural } \\
\text { community of Aboriginal and Torres } \\
\text { Strait Islanders are discussed. } \\
\text { Outlined in the paper is the process } \\
\text { for developing a detailed MOU } \\
\text { between the research team, Aboriginal } \\
\text { health services, and a community- } \\
\text { owned education group. }\end{array}$ \\
\hline
\end{tabular}


Table 2. CIHR Guidelines: Demonstration of Principled Research Practices Described in Articles with Examples (continued)

CIHR Guidelines Key Features: Possible Ways to $\quad$ Examples

Demonstrate Principles

Principle \#14: Interpretation and Dissemination of Research

Article 14:

"An Indigenous community should have an opportunity to participate in the interpretation of data and the review of conclusions drawn from the research to ensure accuracy and cultural sensitivity of interpretation" (CIHR, 2007, p. 26).
- Encourage co-authorship/copresentations to community, researcher, and other identified stakeholders (by Indigenous and Western-oriented research partners).

- Ensure evidence that final results were viewed and agreed upon by all in the research partnership.

- Show evidence that, at the start of the project, all in the research partnership understood that they would have the opportunity to be involved in data interpretation.

- Confirmations with Indigenous community partners for permissions, during data interpretation, dissemination.
In an evaluation study on how a Community Action Research Team (CART) and mentors experienced their role in a study addressing the high rates of sexually transmitted infections in four communities within Northwest Territories, Hopkins (2012) described that a model for place-based knowledge exchange was developed. The work of the CART is community driven, builds capacity, and offers mutual support, and originally comprised of young Tłicho parents who wanted to improve the health and well-being of Tłicho community members.

\section{Article 15:}

"An Indigenous community should, at its discretion, be able to decide how its contributions to the research project should be acknowledged. Community members are entitled to due credit and to participate in the dissemination of results. Publications should recognize the contribution of the community and its members as appropriate, and in conformity with confidentiality agreements" (CIHR, 2007, p. 26).
- Ensure that dissemination is planned by and with community (for example, in research agreement, protocols).

- Identify and document clear roles for those in the research partnership identified.

- Offer opportunities for community stakeholders involved in research to copublish, co-present, and use research.
In a study by Bisset Cargo, Delormier, Macaulay, and Potvin (2004), Indigenous co-researchers played a key role in ensuring that research findings led to applied practice. The study was on the prevention of Type 2 diabetes and used a participatory action research approach that involved many key community stakeholders throughout the study.

\section{Principle \# 15: Memoranda of Understanding and Research Agreements}

"Where a researcher does not have a prior relationship with an Aboriginal community, the latter may have expectations regarding what the researcher should do in order to be prepared for, and to be accepted by, the community-prior to negotiation of a formal research agreement. The expectations of the community and of the researcher may be appropriately addressed in a non-binding Memorandum of Understanding, which would also include the steps to be taken to reach a binding research agreement. However, the relationship-building process is contextual and community specific, and there is no set formula for building such a relationship" (CIHR, 2007, p. 260). 


\section{Discussion}

Western-oriented academic research groups and institutions need to have guidance about how to expand their approaches to research so as to value and respect Inuit, Métis, and First Nations leadership, governance, decision-making, and knowledge systems. The CIHR Guidelines promote the use of Indigenous and Western-oriented knowledge systems together and serve as a resource to support the development and conduct of participatory research. A number of research studies have been conducted between Indigenous and Western-oriented partners since the development of the CIHR Guidelines.

\section{CIHR Guidelines Promote the Use of Indigenous and Western-Oriented Knowledge Systems Together}

Research is essential to guide improvements in health systems and develop new initiatives. When done in ways that those in the partnership can identify as ethical and equitable, participatory research (research that promotes collaboration) can promote a democratic approach to co-creation of evidence (Jull, Giles, \& Graham, 2017). Dialogue that aims to promote respect for differing worldviews and address colonial structures in knowledge production has been defined as an ethical act (Ermine, Sinclair, \& Browne, 2005). Mi'kmaw Elders Murdena and Albert Marshall, with Dr. Cheryl Bartlett, introduced the concept of "Etuaptmumk Two-Eyed Seeing" (Bartlett, Marshall, \& Marshall, 2012). Etuaptmumk is the Mi'kmaw word for Two-Eyed Seeing and "refers to learning to see from one eye with the strengths of Indigenous knowledges and ways of knowing, and from the other eye with the strengths of Western knowledges and ways of knowing" (Institute for Integrative Science \& Health, n.d., para. 1).

Two-Eyed Seeing has been described as a theoretical framework that includes both Indigenous and Western-oriented worldviews. The Two-Eyed Seeing approach incorporates and acknowledges diverse perspectives that honour and accept many forms of knowledge (Martin, 2012). The respect and inclusion of different forms of knowledge creates an "ethical space" for many forms of knowledge, including Indigenous knowledge (Coleman, Battiste, Henderson, Findlay, \& Findlay, 2012; Wilson, 2008). The term "ethical space" was originally conceived of by Roger Poole (Poole, 1972) to identify an abstract space in which there is an interaction of different groups and worldviews. Ermine, Sinclair, and Jeffery (2004) write about the importance of creating an ethical space in which disparate cultural practices and ways of knowing and being can bridge the divide between Indigenous and Western knowledge. According to Ermine et al. (2004), ethical space as a concept is a process that occurs throughout the research process: "each played out in many different codes and relationships at the level of research practice” (p. 21). Ethical space is also described as requiring affirmation to confirm acceptance of cultural differences. Another important feature of ethical space is open discussion about intentions, values, and underlying and explicit assumptions of research that can lead to agreement to interact across a cultural divide (Ermine et al., 2004). Two-Eyed Seeing is expressed as a First Nations concept; other groups express similar concepts of bringing Indigenous and Western-oriented knowledge together, using different terms (CIHR, 2016).

The intent of the CIHR Guidelines is to promote health through research that aligns with Indigenous values and traditions. Descriptions of the guiding principles for research conduct are included within the text of the articles. The CIHR Guidelines therefore support the use of principles that engage Indigenous and Western-oriented forms of knowledge in research and promotes "products or outcomes, based on 
[Indigenous] input plus the academic knowledge, tools, or techniques contributed by the researcher" (CIHR, 2007, p. 22). As well, the CIHR Guidelines support opportunities for those conducting research to be mutually responsive to one another's contexts, needs, and knowledge systems within the research partnerships. The process of using the CIHR Guidelines may also help identify and put into place plans that create opportunities for research conduct, such as the costs associated with participatory research. For this reason, the use of the CIHR Guidelines can lead to actions that support the expansion of knowledge systems (Figure 1).

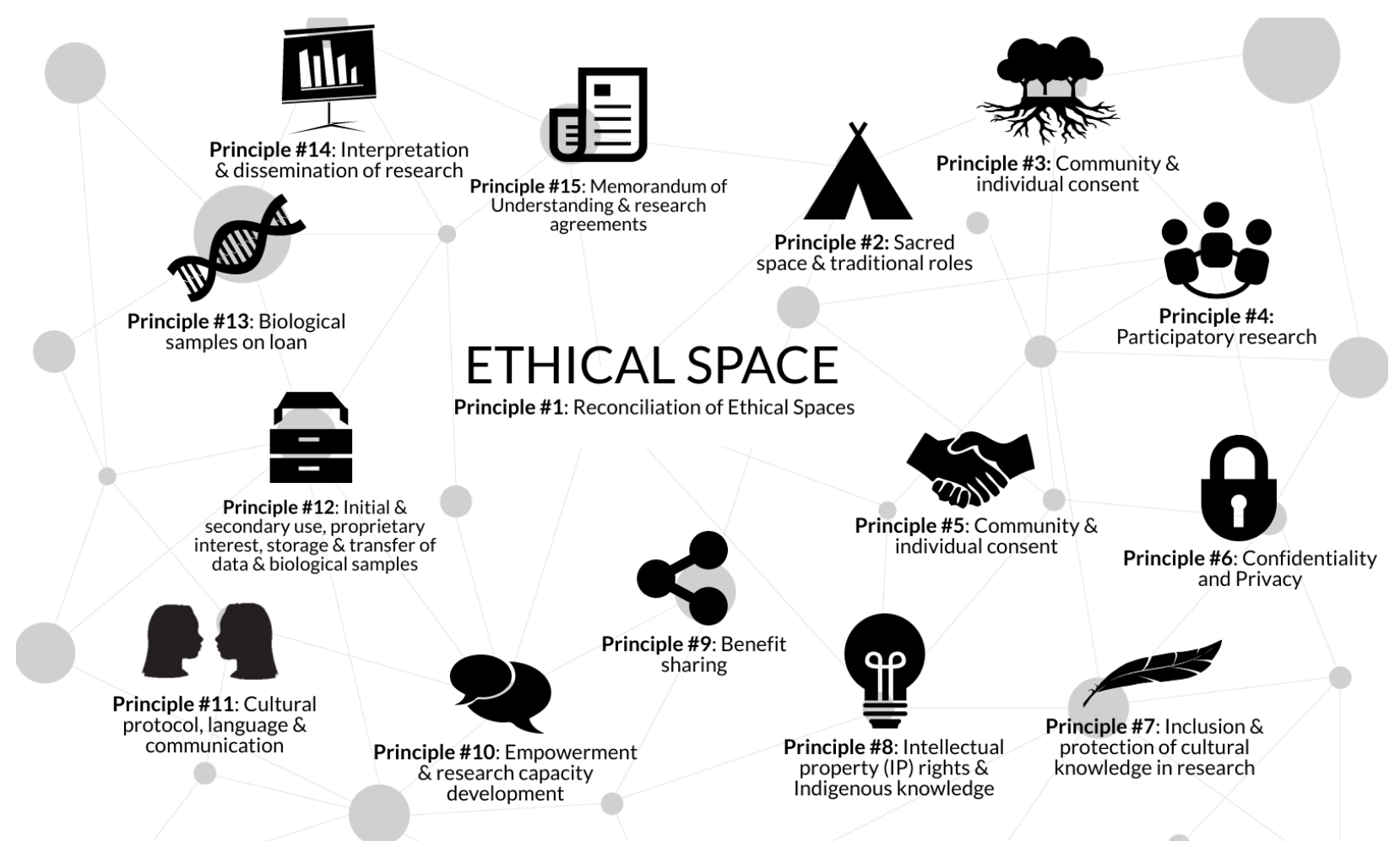

Figure 1. The CIHR Guidelines describe principled research practices.

\section{Examples that Explain the Importance of Engagement in Research}

Fundamental to the CIHR Guidelines is the principle that people with community knowledge have opportunities for engagement in all stages of the research. The opportunities for engagement include defining the need for the study, the approach to the study, the collection of data, the interpretation of results, and the dissemination of findings. For example, in a study conducted about smoking among Métis populations, there was a failure to engage people with relevant community knowledge and this undermined the outcomes of the study. In the example, people with appropriate socio-cultural knowledge were not involved in the interpretation of culturally meaningful data. The non-participatory research approach led to potentially negative consequences for application to policy development and future participation by communities and community members in research (King, 2015). 
The damaging effects of failing to engage Indigenous people with relevant expertise in research is evident in another example involving a Saskatchewan-based study of HIV susceptibility conducted by Western-oriented researchers. The study concluded that the HIV strain circulating in the province of Saskatchewan could lead to more rapid development of AIDS-defining illness due to the resistance of the HIV strain that had adapted to common host immunity profiles (Brumme et al., 2018). Despite anonymization of the data, it is well known that close to $80 \%$ of the HIV cases in Saskatchewan occur in the $16 \%$ of the population that identify as Indigenous (Government of Saskatchewan, 2016). In the study, a clearly identified and reported-on Indigenous population did not have opportunities for engagement in any aspect of the study. As a result, those conducting the study may have further stigmatized Indigenous people living with HIV and increased the distrust of medical and research communities. The issues with the study are multiple and include problematic de-identification, a need for meaningful research ethics board review that balances researcher and community and collective interests, and scientific rigor when studying Indigenous peoples' health (Chelico et al., 2020). In this example, those who conducted the study missed an opportunity to engage the groups who the research impacted through the interpretation and dissemination of the study results, which would have helped ensure that the research findings were conveyed in non-stigmatizing ways. The example provides an opportunity to understand research ethics as an "ongoing and changing process" (Chelico et al., 2020, p. 3 ). Research that is done "to" Indigenous people fails to uphold Indigenous self-determination (Chelico et al., 2020). To avoid potential research harms, it is imperative that participatory approaches are used to foster collaboration in research with Indigenous people.

There are examples of communities and researchers working in the collaborative manners promoted by the CIHR Guidelines to develop research agendas and then co-create and disseminate research knowledge in beneficial ways, as promoted by the CIHR Guidelines. One example is a research study conducted by a community-based and academic team that used a Two-Eyed Seeing approach to develop dementia fact sheets for Indigenous populations that blend Indigenous understandings of illness and caregiving with a Western-oriented disease framework (Jacklin, Warry, Blind, Webkamigad, \& Jones, 2017). In another example, the Water Journey project was conducted by a research collaboration of Elders, Indigenous people with lived HIV and/or hepatitis C experience, and academically trained community-based researchers. Together, the members of the research collaboration defined and implemented a research study that met community needs and was trauma-informed and interwoven with ceremony. The members of the research collaboration developed and approved the final research results (Kallos et al., 2017). Collaborative research practices can create opportunities and space within institutional academic settings for different knowledges to coexist and improve health and social systems (Jull et al., 2018). A principled approach to research supports opportunities for development of knowledge that is useful, relevant, and applicable.

\section{CIHR Guidelines Require Regular Review for Relevance}

Innovations on research models and approaches that address power balances mean that, while the principles of the CIHR Guidelines are relevant today, they may require updating. In addition, the original plan was that the CIHR Guidelines would require regular review for relevance (CIHR, 2007). There is a growing number of community-based researchers and community-engaged research projects that include Elders and Indigenous people with experiences as active members of research teams, Knowledge Holders, et cetera (see Table 2 for examples). There are also ongoing challenges in the 
conduct of these studies, for example within larger epidemiological studies, and there is a need for the recognition of the diverse and multicultural nature of Indigenous communities. Indigenous and Western-oriented researchers are still operating in predominantly Western-oriented academic research systems (Morton Ninomiya \& Pollock, 2017). For this reason, there may be a need to review and update the principles and content of CIHR Guidelines for relevance to better meet the needs of Indigenous and Western-oriented researchers and support a principled approach to change in research relationships.

We have included examples of studies that demonstrate principles of research defined in the CIHR Guidelines (CIHR, 2007) in Table 2. We propose that the approach to research by Western-oriented researchers or institutions in the area of Indigenous health and wellness be contextualized and responsive to individual and community ways of knowing and doing. The CIHR Guidelines describe how to conduct research that demonstrates an ongoing commitment to debate and reflection upon research processes in ways that bring forward the unique needs of Indigenous communities, research team members, and local contexts in an ever-changing society. The principles and content of the CIHR Guidelines provide a foundation from which research efforts in Canada and internationally can advance in collaborative and strengths-based ways to ensure inclusion and respect for Indigenous individuals and communities.

\section{Conclusion}

We assert that the principles of the CIHR Guidelines hold the potential to guide research with Indigenous people in ways that promote equitable partnerships within Western-oriented academic settings. As well, the CIHR Guidelines may serve as a central document in discussions about the theory and practical approaches to research conducted by and with Inuit, Métis, and First Nations people. Expectations for ethical, collaborative, and culturally supportive research with Indigenous groups have continued to advance and the CIHR Guidelines provide the foundation to continue the development of clear directives on how, exactly, to conduct research that reflects these advances.

The principles described in detail across the articles of the CIHR Guidelines can be used to further research agendas, and (a) draw upon the knowledge and expertise of Inuit, Métis, and First Nations community members and groups, and (b) support opportunities to address issues identified in research collaborations by communities and community members in ways they can define as best. The conduct of participatory research that can promote health and wellness requires equitable research partnerships between Indigenous and Western-oriented team members. It is time to advance and document principled research practices throughout research systems and build upon the CIHR Guidelines.

\section{References}

Aboriginal Affairs and Northern Development Canada. (2007). Progress on the implementation of the Labrador Innu Comprehensive Healing Strategy. Retrieved from https://www.aadncaandc.gc.ca/eng/1100100018923/1100100018924

Akena, F. A. (2012). Critical analysis of the production of Western knowledge and its implications for Indigenous knowledge and decolonization. Journal of Black Studies, 43(6), 599-619. doi: https://doi.org/10.1177/0021934712440448 
Allen, J., Mohatt, G. V., Rasmus, S. M., Hazel, K. L., Thomas, L., \& Lindley, S. (2006). The tools to understand: Community as co-researcher on culture-specific protective factors for Alaska Natives. Journal of Prevention \& Intervention in the Community, 32(1-2), 41-59. doi: https://doi.org/10.1300/J005v32n01 04

Allen, K., \& Flamenbaum, J. (2013). Ethics in the science lifecycle: Broadening the scope of ethical analysis. In S. E. Straus, J. Tetroe, \& I. D. Graham (Eds.), Knowledge translation in health care (pp. 363-377). doi: https://doi.org/10.1002/9781118413555.ch33

Assembly of First Nations. (2017). Implementing the United Nations Declaration on the Rights of Indigenous Peoples. Retrieved from https://www.lakotaconsultingllc.com/uploads/1/8/9/9/ $\underline{18996697 / 17-11-27-i m p l e m e n t i n g-t h e-u n-d e c l a r a t i o n-e n . p d f ~}$

Axelsson, P., Kukutai, T., \& Kippen, R. (2016). The field of Indigenous health and the role of colonisation and history. Journal of Population Research, 33(1), 1-7. doi: https://doi.org/ $\underline{10.1007 / \mathrm{s} 12546-016-9163-2}$

Ball, J., \& Janyst, P. (2008). Enacting research ethics in partnerships with Indigenous communities in Canada: "Do it in a good way." Journal of Empirical Research on Human Research Ethics, 3(2), 33-51. doi: https://doi.org/10.1525/jer.2008.3.2.33

Bartlett, C., Marshall, M., \& Marshall, A. (2012). Two-Eyed Seeing and other lessons learned within a co-learning journey of bringing together Indigenous and mainstream knowledges and ways of knowing. Journal of Environmental Studies and Sciences, 2(4), 331-340. doi: https://doi.org/ $\underline{10.1007 / \mathrm{s} 13412-012-0086-8}$

Baydala, L., Fletcher, F., Worrell, S., Kajner, T., Letendre, S., Letendrem, L., . . Rasmussen, C. (2014). Partnership, knowledge translation, and substance abuse prevention with a First Nations community. Progress in Community Health Partnerships: Research, Education, and Action, $8(2), 145-155$. doi: https://doi.org/10.1353/cpr.2014.0030

Bisset, S., Cargo, M., Delormier, T., Macaulay, A. C., \& Potvin, L. (2004). Legitimizing diabetes as a community health issue: A case analysis of an Aboriginal community in Canada. Health Promotion International, 19(3), 317-326. doi: https://doi.org/10.1093/heapro/dah305

Boffa, J., King, M., McMullin, K., \& Long, R. (2011). A process for the inclusion of Aboriginal people in health research: Lessons from the Determinants of TB Transmission Project. Social Science \& Medicine, 72(5), 733-738. doi: https://doi.org/10.1016/j.socscimed.2010.10.033

Brant Castellano, M., \& Reading, J. (2010). Policy writing as dialogue: Drafting an Aboriginal chapter for Canada's Tri-Council Policy Statement: Ethical Conduct for Research Involving Humans. International Indigenous Policy Journal, 1(2). doi: https://doi.org/10.18584/iipj.2010.1.2.1

Brumme, Z. L., Kinloch, N. N., Sanche, S., Wong, A., Martin, E., Cobarrubias, K. D., .. Joy, J. B. (2018). Extensive host immune adaptation in a concentrated North American HIV epidemic. AIDS, 32(14), 1927-1938. doi: https://doi.org/10.1097/QAD.0000000000001912 
Brunger, F., \& Wall, D. (2016). "What do they really mean by partnerships?” Questioning the unquestionable good in ethics guidelines promoting community engagement in Indigenous health research. Qualitative Health Research, 26(13). doi: https://doi.org/10.1177/ $\underline{1049732316649158}$

Canadian Institutes of Health Research (CIHR). (2007). CIHR guidelines for health research involving Aboriginal people. Retrieved from https://cihr-irsc.gc.ca/e/29134.html

Canadian Institutes of Health Research (CIHR). (2016). Institute of Indigenous Peoples' Health. IIPH strategic plan 2014-2018. Retrieved from https://cihr-irsc.gc.ca/e/49589.html

Canadian Institutes of Health Research (CIHR), Natural Sciences and Engineering Research Council of Canada (NSERC), \& Social Sciences and Humanities Research Council of Canada (SSHRC). Tri-Council Policy Statement: Ethical Conduct for Research Involving Humans (TCPS). Retrieved from https://www.ic.gc.ca/eic/site/063.nsf/eng/h_76504BFE.html

Canadian Institutes of Health Research (CIHR), Natural Sciences and Engineering Research Council of Canada (NSERC), \& Social Sciences and Humanities Research Council of Canada (SSHRC). (2010). Tri-Council Policy Statement: Ethical conduct for research Involving humans (TCPS2). Ottawa, Canada: Author.

Canadian Institutes of Health Research (CIHR), Natural Sciences and Engineering Research Council of Canada (NSERC), \& Social Sciences and Humanities Research Council of Canada (SSHRC). (2014). Tri-Council Policy Statement: Ethical conduct for research involving humans (TCPS2 2014). Retrieved from https://ethics.gc.ca/eng/documents/TCPS 2-2014 FINAL Web.pdf

Canadian Institutes of Health Research (CIHR), Natural Sciences and Engineering Research Council of Canada (NSERC), \& Social Sciences and Humanities Research Council of Canada (SSHRC). (2018). Tri-Council Policy Statement: Ethical conduct for research involving humans-TCPS 2 (2018). Retrieved from https://ethics.gc.ca/eng/documents/tcps2-2018-en-interactivefinal.pdf

Cash, A., De Oliveira, A., Garrick, C., \& Hemi, H. (2014). Beyond epistemic provincialism: Deprovincializing Indigenous resistance. AlterNative: An International Journal of Indigenous Peoples, 10(3), 216-231. doi: https://doi.org/10.1177/117718011401000302

Castleden, H., Morgan, V. S., \& Neimanis, A. (2010). Researchers' perspectives on collective/community co-authorship in community-based participatory Indigenous research. Journal of Empirical Research on Human Research Ethics, 5(4), 23-32. doi: https://doi.org/ $\underline{10.1525 / \text { jer.2010.5.4.23 }}$

Chelico, L., King, A., Ticknor, J., McDonald, M., Rosenes, R., Mercredi, J., Saddleback, J., Bailey, G., King, M., \& Saskatoon Tribal Council Health \& Family Services. (2020). Perspectives of Saskatchewan researchers and community members on HIV-1 strains circulating in Saskatchewan. AIDS. Advance online publicaton. doi: https://doi.org/10.1097/ QAD.0000000000002515 
Coleman, D., Battiste, M., Henderson, S., Findlay, I. M., \& Findlay, L. (2012). Different knowings and the Indigenous humanities. ESC: English Studies in Canada, 38(1), 141-159. doi: https://doi.org/10.1353/esc.2012.0009

Czyzewski, K. (2011). Colonialism as a broader social determinant of health. The International Indigenous Policy Journal, 2(1). doi: https://doi.org/10.18584/iipj.2011.2.1.5

Ermine, W., Sinclair, R., \& Browne, M. (2005). Kwayaskitotamowin: Indigenous research ethics. Retrieved from http://iphrc.ca/pub/documents/ethics review iphrc.pdf

Ermine, W., Sinclair, R., \& Jeffery, B. (2004). The ethics of research involving Indigenous Peoples. doi: https://doi.org/10.13140/RG.2.2.23069.31200

First Nations Information Governance Centre (FNIGC). (2018). The First Nations principles of $O C A P^{\circledast}$. Retrieved from www.fnigc.ca/ocap

Gaudry, A., \& Lorenz, D. (2018). Indigenization as inclusion, reconciliation, and decolonization: Navigating the different visions for Indigenizing the Canadian Academy. AlterNative: An International Journal of Indigenous Peoples, 14(3), 3. doi: https://doi.org/10.1177/ $\underline{1177180118785382}$

Government of Canada. (1996). Report of the Royal Commission on Aboriginal Peoples. Retrieved from http://www.parl.gc.ca/content/lop/researchpublications/prb9924-e.htm

Government of Saskatchewan. (2016). HIV prevention and control report for 2016. Retrieved from http://publications.gov.sk.ca/documents/13/104861-2016-Saskatchewan-HIV-Preventionand-Control-Report.pdf

Health Research Council of New Zealand. (2010). Guidelines for researchers on health research involving Māori 2010. Retrieved from https://www.hrc.govt.nz/sites/default/files/201906/Resource\%20Library\%20PDF\%20-\%20Guidelines\%20for\%20Reseasrchers\%20on \%20Health\%20Research\%20involving\%20Maori\%20.pdf

Hopkins, S. (2012). The Tłįchọ Community Action Research Team: Place-based conversation starters. Pimatisiwin: A Journal of Aboriginal \& Indigenous Community Health, 10(2), 191-205.

Hudson, M., Southey, K., Uerata, L., Beaton, A., Milne, M., Russell, K., .. . Port, W. (2016). Key informant views on biobanking and genomic research with Māori. New Zealand Medical Journal, 129(1447), 29-42.

Indigenous Peoples Council on Biocolonialism. (2000). Indigenous Research Protection Act. Retrieved from http://www.ipcb.org/publications/policy/files/irpa.html

Institute for Integrative Science \& Health. (n.d.). Two-Eyed Seeing. Retrieved from http://www.integrativescience.ca/Principles/TwoEyedSeeing/ 
Inter-Parliamentary Union. (2014). Implementing the UN Declaration on the Rights of Indigenous Peoples: Handbook for Parliamentarians (No. 23). Retrieved from https://www.undp.org/content/dam/undp/library/Democratic\%20Governance/Human\%20 Rights/RightsOfIndigenousPeoples-HandbookForParliamentarians-EN.pdf

Inuit Tapiriit Kanatami. (2018). National Inuit Strategy on Research. Retrieved from https://www.itk.ca/wp-content/uploads/2018/04/ITK_NISR-Report_English_low_res.pdf

Inuit Tapiriit Kanatami, \& Nunavut Research Institute. (2007). Negotiating research relationships with Inuit communities: A guide for researchers. Retrieved from https://www.itk.ca/sites/default/ files/Negotitiating-Research-Relationships-Researchers-Guide.pdf

Israel, B. A, Krieger J., Vlahov, D., Ciske, S., Foley M., Fortini, P., Guzman, R., Lichenstein R., McGranaghan, R., Palermmo, A., \& Tang, G. (2008). Challenges and facilitating factors in sustaining community-based participatory research partnerships: Lessons learned from the Detroit, New York City and Seattle urban research centers. Journal of Urban Health, 83(6), 1022-1040. doi: https://doi.org/10.1007/s11524-006-9110-1

Jacklin, K., \& Kinoshameg, P. (2008). Developing a participatory Aboriginal health research project: "Only if it's going to mean something." Journal of Empirical Research on Human Research Ethics: An International Journal, 3(2), 53-67. doi: https://doi.org/10.1525/jer.2008.3.2.53

Jacklin, K., Warry, W., Blind, M., Webkamigad, S., \& Jones, L. (2017). What is dementia? Indigenous perpectives and cultural understandings. Retrieved from https://141419f0-5602-433d-85d24d5a8ecfd5ec.filesusr.com/ugd/27ba04 7042c9f81bf946feba37b90d9db5261d.pdf

Jull, J., Giles, A., Minwaashin Lodge, the Aboriginal Women's Support Centre, Boyer, Y., \& Stacey, D. (2015). Cultural adaptation of a shared decision making tool with Aboriginal women: A qualitative study. BMC Medical Informatics and Decision Making, 15. doi: https://doi.org/ $\underline{10.1186 / \mathrm{s} 12911-015-0129-7}$

Jull, J., Giles, A., \& Graham, I. D. (2017). Community-based participatory research and integrated knowledge translation: Advancing the co-creation of knowledge. Implementation Science, 12(1), 150. doi: https://doi.org/10.1186/s13012-017-0696-3

Jull, J. E. G., \& Giles, A. R. (2012). Health equity, Aboriginal Peoples and occupational therapy. Canadian Journal of Occupational Therapy, 79(2), 70-76. doi: https://doi.org/10.2182/ cjot.2012.79.2.2

Jull, J., Morton-Ninomiya, M., Compton, I., \& Picard, A. (2018). Fostering the conduct of ethical research practices: The imperative for integrated knowledge transaltion in research conducted by and with Indigenous community members. Research Engagement and Involvement, 4(45). doi: https://doi.org/10.1186/s40900-018-0131-1 
Kahnawake Schools Diabetes Prevention Project (KSDPP). (2007). Kahnawake Schools Diabetes Prevention Project (KSDPP) code of research ethics (revised 2007). Retrieved from https://www.ksdpp.org/media/ksdpp_code_of_research_ethics2007.pdf

Kallos, A., Macklin, C., King, M., Jinkerson-Brass, S., Laframbiose, S.-L., Masching, R., ... King, A. (2017). Water journey: Emerging themes for research priorities for Indigenous Peoples in Canada and hepatitis C. Canadian Journal of Aboriginal Community-Based HIV/AIDS Research, 8, 61-79.

Kelley, A., Belcourt-Dittloff, A., Belcourt, C., \& Belcourt, G. (2013). Research ethics and Indigenous communities. American Journal of Public Health, 103(12), 2146-2152. doi: https://doi.org/ $\underline{10.2105 / \mathrm{AJPH} .2013 .301522}$

King, M. (2015). Contextualization of socio-culturally meaningful data. Canadian Joural of Public Health, 106(6), e457. doi: https://doi.org/10.17269/CJPH.106.5328

King, M., Smith, A., \& Gracey, M. (2009). Indigenous health Part 2: The underlying causes of the health gap. Lancet, 374(9683), 76-85. doi: https://doi.org/10.1016/S0140-6736(09)60827-8

Kowal, E., Pearson, G., Peacock, C. S., Jamieson, S. E., \& Blackwell, J. M. (2012). Genetic research and Aboriginal and Torres Strait Islander Australians. Journal of Bioethical Inquiry, 9(4), 419-432. doi: https://doi.org/10.1007/s11673-012-9391-x

Ly, A., \& Crowshoe, L. (2015). 'Stereotypes are reality': Addressing stereotyping in Canadian Aboriginal medical education. Medical Education, 49(6), 612-622. doi: https://doi.org/10.1111/ $\underline{\text { medu. } 12725}$

Martin, D. H. (2012). Two-Eyed Seeing: A framework for understanding Indigenous and nonIndigenous approaches to Indigenous health research. Canadian Journal of Nursing Research, 44(2), 20-42.

Masuda, J. R., Zupancic, T., Crighton, E., Muhajarine, N., \& Phipps, E. (2014). Equity-focused knowledge translation: A framework for "reasonable action" on health inequities. International Journal of Public Health, 59(3), 457-464. doi: https://doi.org/10.1007/s00038-013-0520-z

Moore, C., Castleden, H. E., Tirone, S., \& Martin, D. (2017). Implementing the Tri-Council policy on ethical research involving Indigenous Peoples in Canada: So, how's that going in Mi'kma'ki? The International Indigenous Policy Journal, 8(2), 4. doi: https://doi.org/10.18584/ iipj.2017.8.2.4

Morton Ninomiya, M. E., \& Pollock, N. (2017). Reconciling community-based Indigenous research and academic practices: Knowing principles is not always enough. Social Science \& Medicine, 172, 28-36. doi: https://doi.org/10.1016/j.socscimed.2016.11.007 
National Aboriginal Health Organization. (2010). Principles of ethical Métis research. Retrieved from https://ruor.uottawa.ca/bitstream/10393/30591/1/PrinciplesofEthicalMetisResearchdescriptive 003.pdf

National Collaborating Centre for Aboriginal Health. (2012). The state of knowledge of Aboriginal health: A review of Aboriginal public health in Canada. Retrieved from https://www.ccnsanccah.ca/docs/context/RPT-StateKnowledgeReview-EN.pdf

National Health and Medical Research Council. (2018). Ethical conduct in research with Aboriginal and Torres Strait Islander Peoples and communities: Guidelines for researchers and stakeholders. Retrieved from https://nhmrc.gov.au/sites/default/files/documents/ Indigenous\%20guidelines/Indigenous-ethical-guidelines.pdf

Noojmowin Teg Health Centre. (2003). Guidelines for ethical Aboriginal research: A resource manual for the development of ethical and culturally appropriate community-based research within the First Nations communities in the Manitoulin area. Retrieved from https://www.noojmowinteg.ca/images/GEAR - FINAL.pdf

Nowgesic, E., Meili, R., Stack, S., \& Myers, T. (2015). The Indigenous Red Ribbon Storytelling Study: What does it mean for Indigenous peoples living with HIV and a substance use disorder to access antiretroviral therapy in Saskatchewan? Canadian Journal of Aboriginal CommunityBased HIV/AIDS Research, 7(1), 27-40.

NunatuKavut Community Council Research Advisory Committee. (2013). Guidelines for community engagement with NunatuKavut. Retrieved from https://nunatukavut.ca/site/uploads/ 2019/05/guide for researchers.pdf

O'Neil, J. D. (1995). Issues in health policy for Indigenous Peoples in Canada. Australian Journal of Public Health, 19(6), 559-566. doi: https://doi.org/10.1111/j.1753-6405.1995.tb00459.x

Pahwa, P., Abonyi, S., Karunanayake, C., Rennie, D. C., Janzen, B., Kirychuk, S., .. . Dosman, J. A. (2015). A community-based participatory research methodology to address, redress, and reassess disparities in respiratory health among First Nations. BMC Research Notes, $8(1)$. doi: https://doi.org/10.1186/s13104-015-1137-5

Poole, R. (1972). Towards deep subjectivity. London, England: Penguin Press.

Reading, J. (2009). The crisis of chronic disease among Aboriginal Peoples: A challenge for public health, population health and social policy. Retrieved from https://dspace.library.uvic.ca/ bitstream/handle/1828/5380/Chronic-Disease-2009.pdf?sequence $=1$ \&isAllowed $=y$

Reading C. L., \& Wien F. (2009). Health inequalities and social determinants of Aboriginal Peoples' health. Retrieved from https://www.ccnsa-nccah.ca/docs/determinants/RPTHealthInequalities-Reading-Wien-EN.pdf 
Samediggi, S. (2018). Proposal for ethical guidelines for Sámi health research and research on Sámi human biological material. Retrieved from https://www.sametinget.no/content/ download/2341/file/Proposal\%20for\%20Ethical\%20Guidelines\%20for\%20S\%C3\%A1mi\%20 Health\%20Research\%20and\%20Research\%20on\%20S\%C3\%A1mi\%20Human\%20Biological\% 20Material.pdf

Smith, L. T. (2012). Decolonizing methodologies: Research and Indigenous Peoples. New York, USA: Zed Books Ltd.

Smylie, J. K., Olding, M., \& Ziegler, C. (2014). Sharing what we know about living a good life: Indigenous approaches to knowledge translation. Journal of the Canadian Health Libraries Association, 35(01), 16-23. doi: https://doi.org/10.5596/c14-009

Taniguchi, N., Taualii, N., \& Maddock, J. (2012). A comparative analysis of Indigenous research guidelines to inform genomic research in Indigenous communities. The International Indigenous Policy Journal, 3(1). doi: https://doi.org/10.18584/iipj.2012.3.1.6

Tobias, J. K., Richmond, C. A. M., \& Luginaah, I. (2013). Community-based participatory research (CBPR) with Indigenous communities: Producing respectful and reciprocal research. Journal of Empirical Research on Human Research Ethics: An International Journal, 8(2), 129-140. doi: https://doi.org/10.1525/jer.2013.8.2.129

Truth and Reconcilliation Commission of Canada (2015a). Truth and Reconciliation Commission of Canada: Calls to Action. Retrieved from http://trc.ca/assets/pdf/Calls to Action English2.pdf

Truth and Reconciliation Commission. (2015b). Honouring the truth, reconciling for the future: Summary of the final report of the Truth and Reconciliation Commission of Canada. Retrieved from http://www.trc.ca/assets/pdf/Honouring the Truth_Reconciling for the Future July_23_2015.pdf

United Nations. (n.d.). Indigenous Peoples at the United Nations. Retrieved from https://www.un.org/development/desa/indigenouspeoples/about-us.html

United Nations. (2007). United Nations Declaration on the Rights of Indigenous Peoples. Retrieved from https://www.un.org/development/desa/indigenouspeoples/wpcontent/uploads/sites/19/2018/11/UNDRIP_E_web.pdf

Walker, J., Lovett, R., Kukutai, T., Jones, C., \& Henry, D. (2017). Indigenous health data and the path to healing. The Lancet, 390(10107), 2022-2023. doi: https://doi.org/10.1016/S0140-6736 (17)32755-1

Warry, W. (1990). Doing unto others: Applied anthropology, collaborative research and Native selfdetermination. Culture, $10(1), 61-73$. 
Wilk, P., Cooke, M., Stranges, S., \& Maltby, A. (2017). Reducing health disparities among Indigenous populations: The role of collaborative approaches to improve public health systems. International Journal of Public Health, 63(1), 1-2. doi: https://doi.org/10.1007/ $\underline{\text { s00038-017-1028-8 }}$

Wilson, S. (2008). Research is ceremony: Indigenous research methods. Halifax, Canada: Fernwood Publishing.

World Health Organization. (n.d.). Indigenous Peoples and participatory health research. Retrieved from http://www.who.int/ethics/indigenous_peoples/en/index2.html

Yukon Research Centre. (2013). Protocols and principles for conducting research with Yukon First Nations. Retrieved from https://www.yukoncollege.yk.ca/sites/default/files/inlinefiles/YRC_FN_Initiatives no photos inside final print $0 . \mathrm{pdf}$ 